\title{
Aminosalicylate Sodium
}

National Cancer Institute

\section{Source}

National Cancer Institute. Aminosalicylate Sodium. NCI Thesaurus. Code C47958.

The sodium salt form of aminosalicylic acid, an analog of para-aminobenzoic acid (PABA) with antitubercular activity. Aminosalicylate sodium exerts its bacteriostatic activity against Mycobacterium tuberculosis by competing with PABA for enzymes involved in folate synthesis, thereby suppressing growth and reproduction of M. tuberculosis, eventually leading to cell death. 